\title{
Echocardiographic diastolic abnormalities of the left ventricle in inflammatory joint disease
}

\author{
I F Rowe, D G Gibson, A C S Keat, D A Brewerton
}

\begin{abstract}
Echocardiographic early diastolic abnormalities have been shown recently in $50 \%$ of men with ankylosing spondylitis. Similar techniques were used to investigate subjects with rheumatoid arthritis and psoriatic arthritis with or without spondylitis. These subjects had no clinical, radiographic, or electrocardiographic evidence of cardiac or respiratory disease. Echocardiographic abnormalities seen resembled those of ankylosing spondylitis in that the interval between minimum left ventricular dimension and mitral valve opening was prolonged in 12 of 22 subjects with rheumatoid arthritis and in seven of 11 subjects with psoriatic arthritis. Isovolumic relaxation time was significantly prolonged in four subjects with rheumatoid arthritis and one with psoriatic arthritis. Unlike ankylosing spondylitis, however, there was consistent reduction in peak rate of left ventricular dimension increase in subjects with rheumatoid arthritis and psoriatic arthritis. In addition, the dimension increase during atrial systole was greater than normal in nine subjects with rheumatoid arthritis and two with psoriatic arthritis. The most likely cause of these abnormalities is increased connective tissue deposition in the myocardium.
\end{abstract}

Echocardiographic diastolic abnormalities of the left ventricle have recently been shown in 16 of 30 men with ankylosing spondylitis. ${ }^{1}$ These subjects had no cardiorespiratory symptoms or known clinical abnormalities of heart or lungs; chest radiographs and standard electrocardiograms were normal in all except one subject with minor ST segment changes. Early diastolic abnormalities included notably an increase in the intervals: minimum left ventricular dimension to mitral valve opening (MD-MVO); and phonocardiographic $A_{2}$ to mitral valve opening (isovolumic relaxation time). The clinical significance of these findings is not known, though ankylosing spondylitis is known to be associated with a small but significant excess mortality, ${ }^{2}$ and a mild, diffuse increase of interstitial connective tissue has been found in the myocardium of patients with ankylosing spondylitis at necropsy. ${ }^{1}$

Rheumatoid arthritis is associated with an increased mortality from various causes ${ }^{3}$; some ${ }^{4-6}$ but not all $^{7} 8$ studies report an excess incidence of deaths from cardiac disease. Pericarditis is well recognised in rheumatoid arthritis, and about $40 \%$ of patients may show evidence of chronic pericarditis at necropsy. ${ }^{9}$ Echocardiographic studies in rheumatoid arthritis have confirmed pericardial disease, which is often clinically non-apparent, and minor abnormalities of the mitral valve. ${ }^{10-13}$ Although histological studies of the myocardium are few, various lesions have been reported, including granulomata, arteritis, and myocarditis. ${ }^{14-16}$

This investigation aimed at determining, with echocardiographic techniques similar to those used in the study of men with ankylosing spondylitis, ${ }^{1}$ whether diastolic left ventricular abnormalities occur in women with spondylitis, and in subjects with other forms of chronic inflammatory joint disease, including psoriatic arthritis with or without spondylitis, and rheumatoid arthritis.

\section{Patients and methods}

The following were referred for echocardiography: 38 subjects fulfilling the criteria for definite or classical rheumatoid arthritis according to the criteria of the American Rheumatism Association, ${ }^{17} 17$ subjects with psoriatic arthritis, including six with spondylitis, as described by Moll and Wright ${ }^{18}$; one woman with psoriasis, spondylitis, and Crohn's disease; and six women with spondylitis who fulfilled the New York criteria for ankylosing spondylitis. ${ }^{19}$ All patients were aged between 20 and 60 and had no relevant cardiorespiratory symptoms or known heart or lung disease. Clinical examination of the cardiovascular and respiratory systems, chest radiograph, and standard 12-lead resting electrocardiograms were normal. Controls were subjects who had no known disease and were not particularly athletic but were attending a fitness clinic.

Of the $M$ mode echocardiograms, only $22 / 38$ (58\%) from subjects with rheumatoid arthritis and 11/17 (65\%) from those with psoriatic arthritis were of sufficiently high quality to allow accurate digitisation for assessment of diastolic function, though all would have been of suitable standard for routine clinical purposes. The proportion digitised was similar to that in other studies, including that of subjects with ankylosing spondylitis ${ }^{1}$ in whom quality of echocardiograms was not influenced by spinal deformity. Those patients in whom echocardiograms were not suitable for digitisation did not differ in age, disease severity, or duration of disease from those in whom further analysis was possible.

The table summarises the clinical details of patients with rheumatoid arthritis and psoriatic 
Clinical details of patients with rheumatoid arthritis and psoriatic arthritis analysed by echocardiography

\begin{tabular}{lll}
\hline $\begin{array}{l}\text { Clinical } \\
\text { detail }\end{array}$ & $\begin{array}{l}\text { Rheumatoid } \\
\text { arthritis }\end{array}$ & $\begin{array}{c}\text { Psoriatic } \\
\text { arthritis }\end{array}$ \\
\hline $\begin{array}{l}\text { Number analysed } \\
\text { Male:female }\end{array}$ & 22 & 11 \\
Age (years) & $2: 20$ & $5: 6$ \\
$\quad$ Mean & 45 & 41 \\
$\quad$ Range & $28-60$ & $20-60$ \\
Duration of arthritis (years) & 13 & 11 \\
$\quad$ Mean & $1-28$ & $3-20$ \\
$\quad$ Range & 0 & 4 \\
Spondylitis & 17 & 0 \\
Seropositive & 17 & 0 \\
Prednisolone treatment & & 0 \\
Gold/D-penicillamine treatment & 17 & 0 \\
\hline
\end{tabular}

*Treatment was current or previously.

arthritis in whom suitable measurements were made. It was possible to analyse only one woman with ankylosing spondylitis. She was aged 30 years with a 12 year history of spondylitis, with mild restriction of spinal movement. She was HLA-B27 positive and had radiographic evidence of sacroiliitis. The woman with psoriasis, spondylitis, and Crohn's disease was aged 34 years, and had had these conditions for 18,16 , and 15 years respectively. In addition, both her father and brother had spondylitis; her father had died suddenly at the age of 53 and her brother had been analysed in the previous echocardiographic study ${ }^{1}$ and had a markedly prolonged MD-MVO interval (120 ms).

$M$ mode and cross sectional echocardiograms were performed with subjects in the partial left lateral position. $M$ mode echocardiograms of the left ventricle (at the level of the mitral valve tips and showing clear continuous echoes from the septum and posterior wall) were recorded at $10 \mathrm{~cm} / \mathrm{s}$. Left ventricular posterior wall and septal thickness were measured (in $\mathrm{cm}$ ) at end diastole. The echocardiograms were digitised manually, and from their recordings the following measurements were made and their means calculated from three cardiac cycles: $(a)$ systolic and diastolic left ventricular cavity dimensions in $\mathrm{cm}$; $(b)$ minimum left ventricular dimension to mitral valve opening in ms (MD-MVO); (c) interval from phonocardiographic $A_{2}$ to mitral valve opening in $\mathrm{ms}$, which was taken as isovolumic relaxation time; and $(d)$ peak rate of increase of cavity dimensions during early diastole in $\mathrm{cm} / \mathrm{s}$. The results of the echocardiographic studies in each group of patients were compared with those for controls by the MannWhitney test.

\section{Results}

On echocardiography, left ventricular cavity size and wall thickness were normal in all subjects studied. In no subjects were abnormalities of aortic or mitral valve seen, and no patients with rheumatoid arthritis had evidence of pericardial effusion.

The interval MD-MVO was prolonged in 12 of 22 subjects with rheumatoid arthritis (mean (SD) of group 34 (30) ms; $p<0.02$ with respect to normal controls) and in seven of 11 subjects with psoriatic arthritis (mean (SD) $36(28) \mathrm{ms}$; $\mathrm{p}<0.002$ ), three of whom also had spondylitis. These figures compare with the previous report of 29 (24) $\mathrm{ms}$ in ankylosing spondylitis ${ }^{1}$ and with 9 (7) $\mathrm{ms}$ in controls (fig 1). Prolongation of MD-MVO $(60 \mathrm{~ms})$ was also noted in the one female patient with ankylosing spondylitis in whom the echocardiograph was suitable for digitisation. Significant prolongation of isovolumic relaxation time occurred in four subjects with rheumatoid arthritis and one with psoriatic arthritis (fig 2), though the means for the two groups were normal.

Unlike patients with ankylosing spondylitis, ${ }^{1}$ there was consistent reduction in the peak rate of increase of cavity dimensions during early diastole in subjects with rheumatoid arthritis (mean (SD) $11(2.9) \mathrm{cm} / \mathrm{s} ; \mathrm{p}<0.01)$ and in subjects with psoriatic arthritis $(10(4.5) \mathrm{cm} / \mathrm{s}$; $\mathrm{p}<0.05)$ compared with normal controls (15 (2) $\mathrm{cm} / \mathrm{s}$ ). In addition, the dimension increase during atrial systole was greater than normal in nine patients with rheumatoid arthritis and two with psoriatic arthritis.

The diastolic abnormalities recorded in subjects with rheumatoid arthritis and psoriatic arthritis were not related to age (youngest patient with prolonged MD-MVO was 28 years) nor to duration of disease (shortest duration, one year). In those with rheumatoid arthritis there was also no apparent correlation with extra-articular manifestations, nodules, vasculitis, or with particular drug treatment, including gold, penicillamine, or corticosteroids.

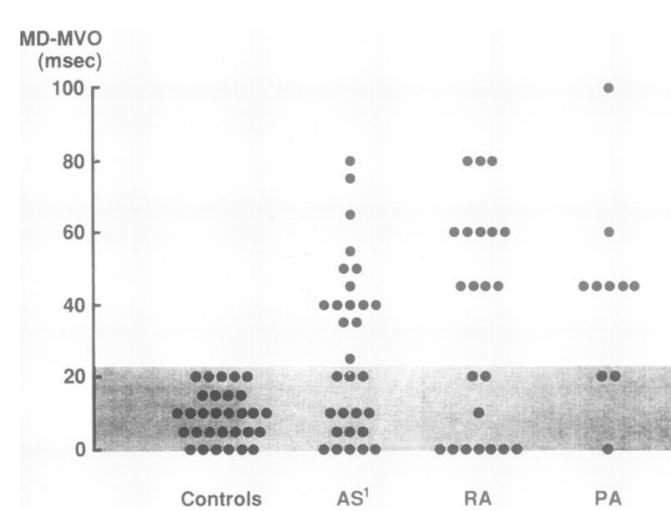

Figure 1 Minimum left ventricular dimension to mitral valve opening (MD-MVO) interval for controls, subjects with ankylosing spondylitis $(A S),{ }^{I}$ rheumatoid arthritis $(R A)$, and psoriatic arthritis $(P A)$. Shaded areas indicate $95 \%$ confidence intervals in controls.

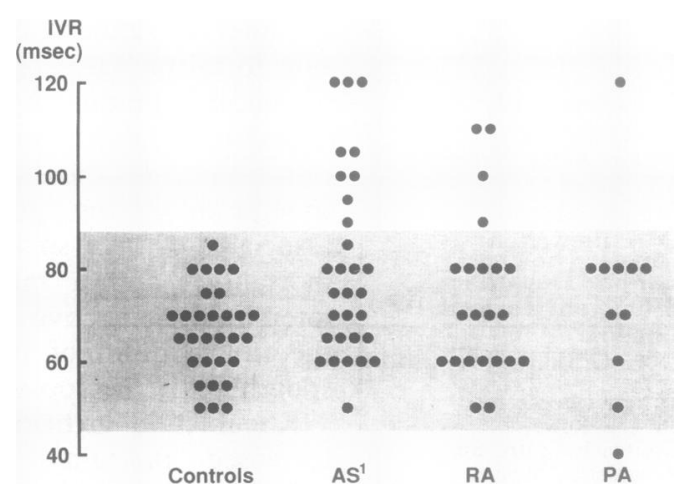

Figure 2 Isovolumic relaxation time (IVR) for controls, subjects with ankylosing spondylitis $(A S),{ }^{1}$ rheumatoid arthritis $(R A)$, and psoriatic arthritis $(P A)$. Shaded areas indicate $95 \%$ confidence intervals in controls. 
The patient with psoriasis, spondylitis, and Crohn's disease also had mild abnormalities of left ventricular filling. There was, however, in addition, a significant increase in myocardial echo intensity, particularly in the subendocardial region towards the apex involving septum and posterior wall. This was thought almost certainly to represent myocardial fibrosis.

\section{Discussion}

Our study differs from previous echocardiographic studies of patients with rheumatoid arthritis in the initial selection of only subjects with no clinical evidence of heart disease. The abnormalities we identified are similar, if possibly more marked, to those occurring in ankylosing spondylitis ${ }^{1}$; they are clearly not confined to subjects with spondylitis, occurring also in those with psoriatic arthritis without spondylitis and in subjects with rheumatoid arthritis.

The early diastolic abnormalities noted are not characteristic of coronary artery disease, conduction defects, or valvular disease. Similarly, they do not represent the usual findings in amyloidosis, myocarditis, or systemic sclerosis. These diastolic abnormalities indicate an alteration in the mechanism underlying normal rapid early diastolic filling of the left ventricle. This mechanism depends on the integrity of normal ventricular restoring forces, which are likely to be elastic in nature. They allow energy stored from the previous systole to be coupled to early diastolic inflow from the left atrium into the left ventricle. An increased MD-MVO and isovolumic relaxation time have been reported in patients with left ventricular hypertrophy secondary to hypertension or hypertrophic obstructive cardiomyopathy, ${ }^{20}$ but there was no evidence on echocardiogram, electrocardiogram, or chest radiograph to suggest these conditions in our patients. Similar left ventricular disturbances without ventricular hypertrophy have also been noted in men with diabetes mellitus, especially in those with microangiopathy. ${ }^{21}$ They have not previously been reported in echocardiographic studies of patients with rheumatoid arthritis, ${ }^{10-13} 22$ though Bacon and Gibson suggested the possibility of left ventricular disease in rheumatoid arthritis on the basis of a reduced diastolic closure rate of the mitral valve. ${ }^{11}$ More recently, abnormalities of diastolic function have been reported in patients with active systemic lupus erythematosus. ${ }^{23}$

The diastolic abnormalities in patients with rheumatoid arthritis and psoriatic arthritis were not related to age or to duration of disease, and in those with rheumatoid arthritis there was also no relation to extra-articular manifestations, nodules, or vasculitis. Although no tissue typing studies were performed in our patients, the occurrence of similar abnormalities in diseases with different HLA associations argues against a genetic predisposition. Similarly, these findings are not apparently related to drug treatment, including corticosteroids or second line treatment for rheumatoid arthritis. All our patients had received non-steroidal antiinflammatory drugs during their illness; the recent finding of similar echocardiographic abnormalities in patients with psoriasis without joint disease who had not received non-steroidal anti-inflammatory drugs indicates that abnormal diastolic function is not related to these drugs and indeed that diastolic abnormalities are not confined to subjects with arthritis (Rowe I F, Gibson D G, Rowland-Payne C M E, Brewerton D A, unpublished data).

The diastolic abnormalities noted represent a functional disturbance of the left ventricle, and the most likely cause of this is an increase or modification of the interstitial connective tissue within the myocardium. Such an increase was noted in patients with ankylosing spondylitis at necropsy ${ }^{1}$; although myocarditis has been reported in rheumatoid arthritis, ${ }^{14}{ }^{16}$ no similar connective tissue deposition has yet been reported in this condition. The echocardiographic features of fibrosis we found in one of our series, however, support this possibility. Inflammation in sites distant from the heart, such as joints, may cause the release of cytokines into the circulation, which promote the deposition or modification of connective tissue in the myocardium, and which in turn leads to minor changes in the mechanism underlying rapid filling. Possibly, also, these diastolic abnormalities are part of a generalised process with alterations in connective tissue deposition in other tissues. The effect of such deposition on early diastolic function may allow its detection in the myocardium more easily than elsewhere.

The clinical significance of our observations is not clear; a minor reduction in early diastolic filling of the left ventricle is compensated by an increase in the proportion of the stroke volume entering with atrial systole or overridden by an increase in left atrial pressure. There is currently no evidence to suggest that this indicates a worse prognosis, but as inflammatory joint diseases are common it is of concern that many fit young subjects with these conditions have abnormal diastolic function. There is clearly a need for a long term controlled follow up study of subjects with these diastolic abnormalities to determine whether there is a subsequent increased morbidity or mortality associated with them. Further investigation into the clinical and pathological nature of these lesions will be important and may yield approaches to prophylactic treatment. It is difficult, however, on the basis of the current evidence to justify invasive procedures such as myocardial biopsy to investigate this further in fit subjects with no apparent heart disease. Further echocardiographic studies of subjects with other inflammatory and non-inflammatory conditions are now in progress. Having shown the presence of abnormal diastolic function in a variety of clinical disorders, we now believe that they may represent a common non-specific consequence of chronic inflammatory disease.

1 Brewerton D A, Gibson D G, Goddard D H, et al. The myocardium in ankylosing spondylitis. A clinical, echocardiographic, and histopathological study. Lancet 1987; i: 995-8.

2 Radford E P, Doll R, Smith P E. Mortality among patients 
with ankylosing spondylitis not given $\mathrm{x}$-ray therapy. $N E n g l$ 7 Med 1977; 297: 572-6.

3 Abruzzo J L. Rheumatoid arthritis and mortality. Arthritis Rheum 1982; 25: 1020-3.

4 Mutru O, Laakso M, Isomaki H, Koota K. Ten year mortality and causes of death in patients with rheumatoid

5 Allebeck P, Ahlbom A, Allander E. Increased mortality among persons with rheumatoid arthritis, but wher rheumatoid arthritis does not appear on the death certificate. Scand f Rheumatol 1981; 10: 301-6.

6 Prior P, Symmons D P M, Scott D L, Brown R, Hawkins C F. Cause of death in rheumatoid arthritis. $\mathrm{Br}\}$ Rheumol 1984; 23: 92-9.

7 Linos A, Worthington V W, O'Fallon W M, Kurland L T The epidemiology of rheumatoid arthritis in Rochester, Minnesota: a study of incidence, prevalence and mortality. Minnesota: a study of incidence, prev

8 Vandenbroucke J P, Hazevoet $H$ M, Cats A. Survival and cause of death in rheumatoid arthritis: a 25 -year prospecive follow up. 7 Rheumatol 1984; 11: 158-61.

9 Sokoloff $L$. The heart in rheumatoid arthritis. Am Heart 7 1953; 45: 635-43.

10 Nomeir A, Turner R, Watts E, et al. Cardiac involvement in rheumatoid arthritis. Ann Intern Med 1973; 79: 800-6.

11 Bacon P A, Gibson D G. Cardiac involvement in rheumatoid arthritis. An electrocardiographic study. Ann Rheum Dis $1974 ; 33: 20-4$

12 MacDonald W J, Crawford M H, Klippel J H, Zvaifler N J, O'Rourke $R$. Echocardiographic assessment of cardiac structure and function in patients with rheumatoid arthritis. Am $\mathcal{7}$ Med 1977; 63: 890-6.

13 Mody G M, Stevens J E, Meyers O L. The heart in rheumatoid arthritis-a clinical and echocardiographic study. $Q$ J Med 1987; 65: 921-8.

14 Lebowitz W B. The heart in rheumatoid arthritis (rheumatoid disease). A clinical and pathological study of sixty-two cases. Ann Intern Med 1963; 58: 102-23.

15 Bonfiglio T, Atwater E C. Heart disease in patients with seropositive rheumatoid arthritis. Arch Intern Med 1969 24: 714-9.

16 Bennett R M. Myocardial involvement. In: Ansell B M Simkin P A, eds. The heart and rheumatic disease. London Butterworth, 1984: 27-64. (Butterworth's International Medical Reviews, Rheumatology 2. )

17 Ropes M W. Diagnostic criteria for rheumatoid arthritis. 1958 Revision. Ann Rheum Dis 1959; 18: 49-53.

18 Moll J H M, Wright V. Familial occurrence of psoriatic arthritis. Ann Rheum Dis 1973; 22: 181-201.

19 Bennet $P \mathrm{H}$, Wood $\mathrm{P} \mathrm{H} \mathrm{N}$. Population studies of the rheumatic diseases. Proceedings of the third international rheumatic diseases. Proceedings of the third international symposium,

20 Shapiro L M, Moore R B, Logan-Sinclair. B B, Gibson D G Relation of regional echo amplitude to left ventricular unction and electrocardiogram in left ventricular hypertrophy. Br Heart f 1984; 52: 99-105.

21 Shapiro L M. Echocardiographic features of impaired ven ricular function in diabetes mellitus. Br Heart f 1982; 47 : 439-44.

22 Voipio-Pulkki L M, Saraste $M$. Left ventricular function in rheumatoid arthritis. Eur Heart f 1987; 8 (suppl J): 105-7.

23 Murai $K$, Oku $H$, Takenchi $K$, Kanayama $Y$, Inoue $T$, Takeda T. Alterations in myocardial systolic and diastolic function in patients with active systemic lupus erythematosus. Am Heart 7 1987; 113: 966-71. 